\title{
Postcardiac injury syndrome, peripheral hematoma of ascending aorta, and cerebral infarction after PCl: a case report
}

\author{
Yuan Wang ${ }^{\dagger}$, Wenkui $\mathrm{Li}^{\dagger}$, Chi Yuan and Hegui Wang ${ }^{*}$ (i)
}

\begin{abstract}
Background: Postcardiac injury syndrome (PCIS) is an inflammatory response syndrome characterized by pericardial effusion with or without pleural effusion; however, serious PCIS with peripheral hematoma of the ascending aorta and acute cerebral infarction after percutaneous coronary intervention (PCI) have not been reported.

Case presentation: This article reports a very rare case of a 40-year-old patient who developed acute pericardial and pleural effusions (both bloody), acute respiratory distress, peripheral hematoma of the ascending aorta, and acute cerebral infarction after PCI. The patient's ECG showed bow-back downward ST elevation in leads I, II, III, and V4-V6. A blood test showed significant increases in eukaryotic-cell count, erythrocyte sedimentation rate (ESR), and C-reactive protein (CRP). Echocardiography and pulmonary artery computed tomography angiography (CTA) showed a large amount of pericardial effusion and pleural effusion. CTA of the thoracic and abdominal aorta showed a peripheral hematoma of the ascending aorta. A cranial computed tomography (CT) showed cerebral infarction anterior to the anterior horn of the right ventricle. After tracheal intubation, ventilator breathing support, pericardial and pleural drainage, and adrenocortical steroid (prednisone) treatment, he gradually recovered and was discharged 20 days later.
\end{abstract}

Conclusion: We report the management of a case of serious PCIS with peripheral hematoma of the ascending aorta and acute cerebral infarction after PCl. Early diagnosis, early differential diagnosis, and early use of steroid therapy are the key in treating PCIS.

Keywords: Postcardiac injury syndrome, Peripheral hematoma, Cerebral infarction, Percutaneous coronary intervention, Prednisone

\section{Background}

Postcardiac injury syndrome (PCIS) is an inflammatory response syndrome characterized by pericardial effusion with or without pleural effusion that is caused by cardiac injuries, usually myocardial infarction (MI) or cardiac surgeries $[1,2]$. In recent years, with rapid advancement in the number, difficulty, and techniques of interventional cardiovascular procedures, such as cardiac

\footnotetext{
* Correspondence: wanghegui@wnmc.edu.cn

†Yuan Wang and Wenkui Li are co-first authors.

Department of Cardiology, Yijishan Hospital of Wannan Medical College, Wuhu, China
}

pacemaker implantation [3], atrial-fibrillation radiofrequency ablation [4], transcatheter aortic-valve implantation (TAVI) [5], and percutaneous coronary intervention (PCI) treatment [6], postoperative PCIS has been reported. Although previous incidences of PCIS have been discussed, there have not yet been reports of PCIS accompanied by peripheral hematoma of the ascending aorta and acute cerebral infarction after PCI.

\section{Case presentation}

A 40-year-old male patient was admitted to the hospital because of poorly controlled hypertension for

(c) The Author(s). 2020 Open Access This article is licensed under a Creative Commons Attribution 4.0 International License, which permits use, sharing, adaptation, distribution and reproduction in any medium or format, as long as you give appropriate credit to the original author(s) and the source, provide a link to the Creative Commons licence, and indicate if changes were made. The images or other third party material in this article are included in the article's Creative Commons licence, unless indicated otherwise in a credit line to the material. If material is not included in the article's Creative Commons licence and your intended use is not permitted by statutory regulation or exceeds the permitted use, you will need to obtain permission directly from the copyright holder. To view a copy of this licence, visit http://creativecommons.org/licenses/by/4.0/ The Creative Commons Public Domain Dedication waiver (http://creativecommons.org/publicdomain/zero/1.0/) applies to the data made available in this article, unless otherwise stated in a credit line to the data. 
more than a decade, recently culminating in a month of chest tightness. Physical examination showed a temperature of $36.4{ }^{\circ} \mathrm{C}$, pulse of 71 beats/min (bpm), respiration rate of 18 breaths $/ \mathrm{min}$, and blood pressure (BP) of $197 / 98 \mathrm{mmHg}(1 \mathrm{mmHg}=0.133 \mathrm{kPa})$. Auscultation revealed clear breath sounds in both lungs, without dry or wet rales. The heart expanded downwards to the left, the heart rhythm was regular, and the heart rate (HR) was $70 \mathrm{bpm}$ without pathological murmurs. ECG showed abnormal inferior-wall Q wave and ST-T change (Fig. 1a). Coronary computed tomography angiography (CTA) revealed that the leftanterior descending (LAD) artery and the right coronary artery (RCA) were 90-95\% narrowed. The patient was given clopidogrel (75 mg, qd), aspirin (100 mg, $\mathrm{qd})$, atorvastatin $(20 \mathrm{mg}, \mathrm{qn})$, and antihypertensive drugs (amlodipine and carvedilol) before percutaneous coronary intervention (PCI).
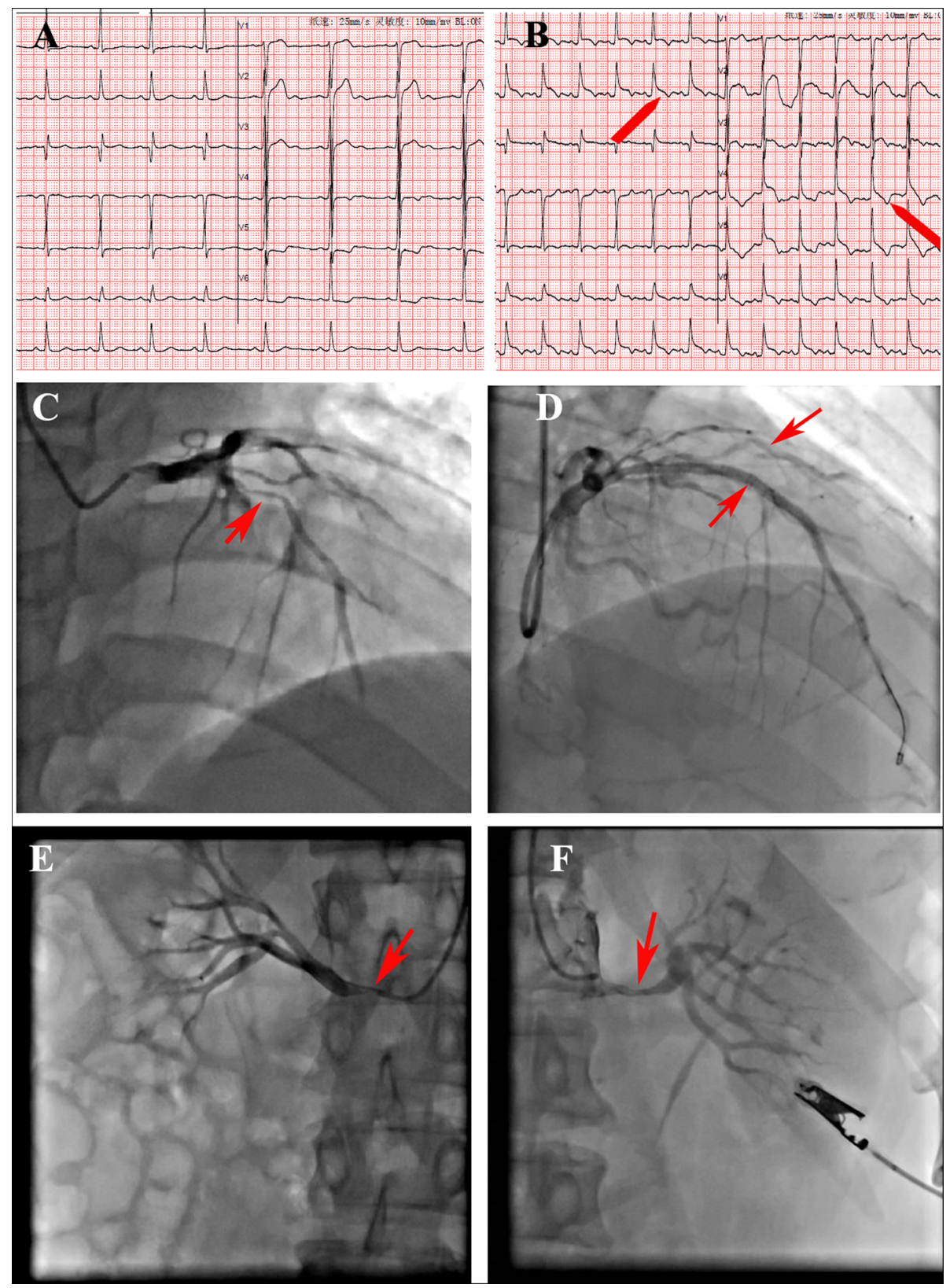

Fig. 1 Dynamic changes in ECG and the results of coronary angiography before and after PCI. a Before PCl. Lead III is QR type, and leads V4-V6 show ST horizontal depression and inverted T wave. b Third day after PCI. Leads I, II, III, and V4-V6 show bow-back downward ST elevation (red arrow). c Severe stenosis in the proximal and middle segments of the LAD before PCI (red arrow). $\mathbf{d}$ The results of two stents implanted in the $L A D$. e Stenosis in the right renal artery (red arrow). $\mathbf{f}$ Stenosis in the left renal artery (red arrow) 
Coronary, renal angiographies, and PCI were performed on the radial artery path. Heparin $(120 \mathrm{U} / \mathrm{kg})$ was used during PCI. The LAD artery was $90 \%$ narrowed in the proximal and middle segments. The D1 was 95\% narrowed in the proximal and middle segments. The right renal artery (RRA) was $80 \%$ narrowed at the opening (Fig. 1e), and the left renal artery (LRA) was $70 \%$ narrowed in the middle segment (Fig. 1f). A 6F EBU 3.5 guide catheter and SION wires were used. Two drug-eluting stents, Firebird $3.0 \times 18 \mathrm{~mm}$ and $3.0 \times 23$ $\mathrm{mm}$, were implanted in the proximal and middle segments of the LAD artery (Fig. 1d). The stent release pressure was 12-14 atm. Percutaneous transluminal coronary angioplasty (PTCA) with a Sprinter $2.0 \times 15 \mathrm{~mm}$ compliant balloon was performed in the D1 proximal end (Fig. 1d). Angiographic results were satisfactory (Fig. $1 \mathrm{c}, \mathrm{d})$.

Three hours after PCI, the patient manifested vomiting, heavy sweating, and wet and cold limbs with irritability. An emergency bedside cardiac ultrasound indicated a small to medium amount of effusion in the pericardial cavity. Pericardiocentesis was performed, and $20 \mathrm{~mL}$ of bloody fluid was drawn. An emergency coronary angiography (CAG) re-examination, performed to confirm the cause of pericardial effusion, showed no coronary perforation or contrast agent leakage or retention; the amount of pericardial effusion was small, which ruled out the possibility of coronary rupture or perforation (Supplementary Fig. 1).

On the third day after PCI, the patient was conscious with respiratory distress and hypoxemia. $\mathrm{SaO}_{2}$ was about 85\%. Pulsus paradoxus could be palpated. ECG showed bow-back downward ST elevation in leads I, II, III, and V4-V6 (Fig. 1b). Pulmonary artery CTA showed a large amount of pericardial effusion and a small amount of pleural effusion, insufficient dilation of both lower lungs, and no significant thrombosis in the bilateral pulmonary arteries (Fig. 2). Emergency pericardiocentesis and catheter drainage were performed, and $190 \mathrm{~mL}$ of bloody liquid was drained. Administration of aspirin $(100 \mathrm{mg}$, qd) was stopped, and the patient was only given clopidogrel (75 mg, qd).

On the fifth day after PCI, the patient's chest tightness and pain could not be alleviated. $\mathrm{SaO}_{2}$ was about $85 \%$, $\mathrm{PCO}_{2}$ was $28.3 \mathrm{mmHg}$, and $\mathrm{PO}_{2}$ was $64.3 \mathrm{mmHg}$. Biochemical test results showed an erythrocyte sedimentation rate (ESR) of $67.9 \mathrm{~mm} / \mathrm{h}$ and C-reactive protein (CRP) was $231.37 \mathrm{mg} / \mathrm{L}$ (Table 1). Ultrasound results showed a small amount of effusion in the pericardial cavity and a large amount in the left thoracic cavity. We performed a left thoracic cavity puncture, and drained $500 \mathrm{~mL}$ of bloody fluid. The patient's condition deteriorated, and bloody pericardial and pleural effusions occurred simultaneously. To rule out the possibility of
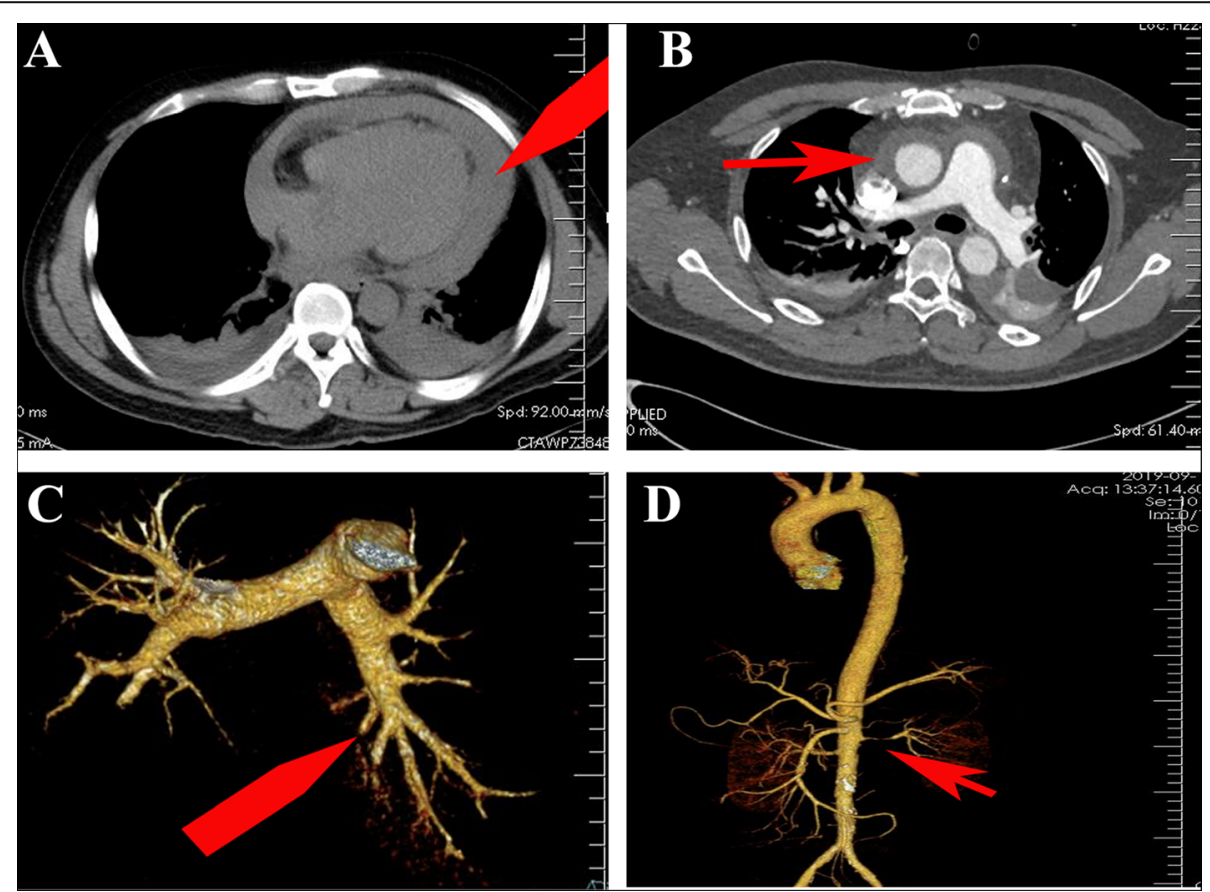

Fig. 2 CTA of pulmonary artery, thoracic aorta, and abdominal aorta. a Moderate amount of pericardial effusion (red arrow) and small amount of pleural effusion. b Peripheral hematoma of the ascending aorta (red arrow). c No niche shadow, filling defect, or obvious thrombosis in the bilateral pulmonary arteries (red arrow). $\mathbf{d}$ No dissection is detected in the thoracic or abdominal aorta CTA, and stenosis of the LRA is revealed (red arrow) 
Table 1 Laboratory test data

\begin{tabular}{|c|c|c|c|c|c|c|c|}
\hline Indicators & Pre-surgery & $3 \mathrm{~h}$ after surgery & 1st day after surgery & 3rd day after surgery & 5th day after surgery & 7th day after surgery & $\begin{array}{l}\text { 20th day } \\
\text { after surgery }\end{array}$ \\
\hline WBCs $(10 \wedge 9 / L)$ & 9.9 & 17.9 & & 15.6 & 15.6 & 13.1 & 12.5 \\
\hline NEUT\% & 71 & 65.1 & & 77 & 89.5 & 75.9 & 70.1 \\
\hline $\mathrm{Hb}(\mathrm{g} / \mathrm{L})$ & 149 & 156 & & 121 & 96 & 103 & 136 \\
\hline $\mathrm{Cr}(\mu \mathrm{mol} / \mathrm{L})$ & 83.2 & 114.3 & & 91.7 & & & 80.2 \\
\hline CRP (ng/L) & & & 15.3 & & 231.3 & & 3.18 \\
\hline ESR (mm/h) & & & & & 69.7 & & 18.8 \\
\hline cTnl (ng/mL) & 0.03 & 0.01 & 0.04 & & 0.14 & 0.09 & \\
\hline $\operatorname{ALT}(\mu / L)$ & 23 & & & & 139 & 175 & 145 \\
\hline AST $(\mu / L)$ & 14 & & & & 63 & 120 & 49 \\
\hline $\mathrm{DD}(\mu \mathrm{g} / \mathrm{mL})$ & 0.19 & & & 1.49 & 1.8 & 3.77 & \\
\hline
\end{tabular}

Notes: WBCs white blood cells, NEUT\% neutrophil percentage, $\mathrm{Hb}$ hemoglobin, $\mathrm{Cr}$ serum creatinine, CRP C-reactive protein, ESR erythrocyte sedimentation rate, $C T n l$ troponin I, ALT alanine aminotransferase, AST aspartate aminotransferase, DD D-dimer

aortic dissection, we performed an emergency CTA examination of the thoracic and abdominal aorta under tracheal intubation and mechanical-assisted ventilation. The results showed a peripheral hematoma of the ascending aorta, without dissection in the thoracic and abdominal arteries, and pleural effusion (Fig. 2). As the patient had PCIS, prednisone $20 \mathrm{mg} / \mathrm{d}$ was administered for anti-inflammatory treatment.

On the seventh day after PCI, the patient's complaint was decreased mobility of the left lower limb. Physical examination showed left-lower-extremity muscle power 0-1. A cranial CT showed cerebral infarction anterior to the anterior horn of the right ventricle (Fig. 3). Aspirin (100 mg, qd) was added, and dual antiplatelet therapy was used. Prednisone $(20 \mathrm{mg} / \mathrm{d})$ anti-inflammatory treatment was continued. The muscle power of the left lower extremity was restored to normal at the twentieth day after PCI. A cardiac ultrasound recheck showed no effusion in the chest and a small amount in the pericardium (supplementary Fig. 2). The prednisone was gradually reduced to $15 \mathrm{mg} / \mathrm{d}$. After tracheal intubation, ventilator breathing support, pericardial and pleural drainage, and adrenocortical steroid (prednisone) treatment, the patient gradually recovered and was discharged 20 days later.

\section{Discussion and conclusions}

PCIS commonly occurs after MI and open-heart surgeries [2]. Its pathogenesis is still not clear, but it is presumed to be immune-mediated in predisposed individuals that develop autoreactive reactions following the initial traumatic event. A diagnosis of PCIS depends on the syndrome's characteristic clinical manifestations. The main features of PCIS are pericardial and/or myocardial damage, pleurisy, fever, leukocytosis, elevated ESR, serum CRP level, and high steroid reactivity [1]. Differential diagnosis should exclude acute pulmonary infarction, aortic dissection, acute MI, pneumonia, congestive heart failure, and possible malignant tumors. The clinical manifestations in this case were mostly consistent with the diagnostic criteria of PCIS, and the patient's condition was very serious. In recent years, other instances of PCIS after PCI treatment have been reported [7].

This patient first manifested with pericarditis and was drained of a large amount of bloody pericardial effusion
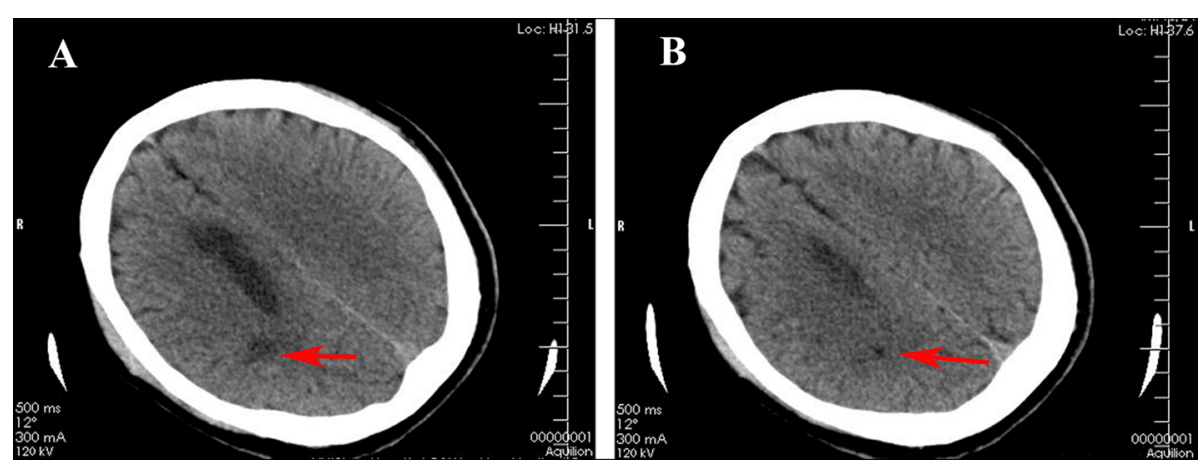

Fig. 3 Cranial CT shows cerebral infarction anterior to the anterior horn of the right ventricle (red arrow) 
$(1500 \mathrm{~mL})$. The blood in the pericardial cavity exacerbated the development and progression of PCIS. The patient demonstrated low fever, increased eukaryotic cell count, and a significant increase in ESR and CRP. After pericardial drainage, chest drainage, and steroid drug treatment, pericardial and pleural effusions were quickly controlled, and ESR and CRP declined rapidly. In this patient, we observed a peripheral hematoma of the ascending aorta via aortic CTA, which might have been caused by a severe immune response induced by cardiac damage. The link between PCIS and ascending aortic hematoma is unclear. One - week post-PCI, the patient showed a decrease in left-lower-extremity muscle power. Cranial CT revealed cerebral infarction anterior to the anterior horn of the right ventricle. Aspirin $(100 \mathrm{mg}$, qd) was immediately added and dual antiplatelet therapy was utilized. A small dose of prednisone was continuously administered. The muscle power of the left lower limb quickly recovered to normal levels, but the mechanism of cerebral infarction remained unclear. The cerebral infarction might have been an embolism, but the patient's ECG showed sinus arrhythmia and we did not find any embolus in the left atrium by multiple echocardiography. In seeking to determine whether the cerebral infarction was an extension of the PCIS process, we searched existing literature and found no related reports. The cerebral infarction might also be related to PCIS, because the patient quickly recovered through drug therapy and the prognosis of the cerebral infarction was good.

In conclusion, to our knowledge, this is the first reported case of serious PCIS, peripheral hematoma of the ascending aorta, and acute cerebral infarction after PCI. Early diagnosis, early differential diagnosis, and early use of steroid hormone therapy are key in treating PCIS.

\section{Supplementary information}

Supplementary information accompanies this paper at https://doi.org/10. 1186/s12872-020-01608-9.

Additional file 1: Supplementary Figure 1. An emergency coronaryangiography (CAG) re-examination at 3 hours after PCl.

Additional file 2: Supplementary Figure 2. Cardiac

echocardiography. A Moderate amount of pericardial effusion on third day after PCl (red arrow). B Tiny amount of pericardial effusion on 19th day after $\mathrm{PCl}$ (red arrow).

\footnotetext{
Abbreviations

PCIS: Postcardiac injury syndrome; ECG: Electrocardiogram; CTAs: Computed tomography angiograms; CT: Computed tomography; MI: Myocardial infarction; PCI: Percutaneous coronary intervention; TAVI: Transcatheter aortic valve implantation; LAD: Left-anterior descending; RCA: Right coronary artery; CAG: Coronary-angiography; ESR: Erythrocyte sedimentation rate; CRP: Creactive protein
}

\section{Authors' contributions}

YW and WKL, the co-first authors, performed the diagnostic coronary angiography for the patient and wrote the manuscript. CY performed the percutaneous coronary intervention. HGW, the corresponding author, performed the percutaneous coronary intervention for the patient, wrote the manuscript, and made the illustrations. All authors read and approved the final manuscript. All authors agreed to their contribution.

\section{Funding}

There is no funding for this study.

\section{Availability of data and materials}

The data analyzed in the case report are not publicly available due to the privacy policy of the hospital, but are available from the corresponding author upon reasonable request.

\section{Ethics approval and consent to participate}

Not applicable.

\section{Consent for publication}

Informed consent for the publication of the case report was obtained from the patient in written form.

\section{Competing interests}

The authors declare that they have no competing interests.

Received: 20 April 2020 Accepted: 29 June 2020

Published online: 03 July 2020

\section{References}

1. Adler Y, Charron P, Imazio M, et al. 2015 ESC guidelines for the diagnosis and management of pericardial diseases: the task force for the diagnosis and Management of Pericardial Diseases of the European Society of Cardiology (ESC) endorsed by: the European Association for Cardio-Thoracic Surgery (EACTS). Eur Heart J. 2015;36:2921-64.

2. Miller RH, Horneffer PJ, Gardner TJ, Rykiel MF, Pearson TA. The epidemiology of the postpericardiotomy syndrome: a common complication of cardiac surgery. Am Heart J. 1988;116:1323-9.

3. Hoshiyama T, Ashikaga K, Tsujita K, Shibata Y. Colchicine reduced pericardial effusion due to postcardiac injury syndrome following cardiac resynchronization therapy implantation. Clin Case Rep. 2017;5:1003-6.

4. Yukumi S, Ichiki H, Funada J, et al. Postcardiac injury syndrome following vascular interventional radiofrequency ablation for paroxysmal atrial fibrillation. Respir Med Case Rep. 2015;15:89-91.

5. Llubani R, Bohm M, Imazio M, Fries P, Khreish F, Kindermann I. The first post-cardiac injury syndrome reported following transcatheter aortic valve implantation: a case report. Eur Heart J Case Rep. 2018;2:yty107.

6. Paiardi S, Cannata F, Ciccarelli M, Voza A. Post-cardiac injury syndrome: an atypical case following percutaneous coronary intervention. Am J Emerg Med. 1985;2017(35):e1-2.

7. Imazio M, Hoit BD. Post-cardiac injury syndromes. An emerging cause of pericardial diseases. Int J Cardiol. 2013;168:648-52.

\section{Publisher's Note}

Springer Nature remains neutral with regard to jurisdictional claims in published maps and institutional affiliations.
Ready to submit your research? Choose BMC and benefit from:
- fast, convenient online submission
- thorough peer review by experienced researchers in your field
- rapid publication on acceptance
- support for research data, including large and complex data types
- gold Open Access which fosters wider collaboration and increased citations
- maximum visibility for your research: over $100 \mathrm{M}$ website views per year
At BMC, research is always in progress.
Learn more biomedcentral.com/submissions 